\title{
Metaphora Analysis on Journalistic Diversity (Discourse Study on Jawa Pos Newspaper)
}

\author{
Subangun ${ }^{1}$, Diyah Atiek Mustikawati ${ }^{2}$ \\ \{pak.b.jozz@gmail.com $\left.{ }^{1}\right\}$ \\ Universitas Muhammadiyah Ponorogo, 63471, Indonesia ${ }^{1,2}$
}

\begin{abstract}
This study aims (1) to explain the form and types of metaphors used in the news discourse of the Jawa Pos newspaper, (2) to explain the similarities between the vehicle and the tenor of metaphoric speech in the news discourse of the Jawa Pos newspaper. In order to analyze the forms and types of metaphors, the agih method is used, with the basic technique for Direct Elements (BUL) and advanced techniques of changing techniques and techniques of changing the form (paraphrasing). To analyze the comparison between the lexical meaning and the metaphorical meaning of the expressions under study, the equivalent method is used. The results of this study are (a) The forms and types of metaphors in the discourse of the Jawa Pos newspaper news can be grouped into four forms, namely the nominative metaphor, complimentative metaphor, predicative metaphor, and sentence metaphor, (b) Metaphors in the discourse of the Jawa Pos newspaper news can categorized into four types, namely anthropomorphic metaphors, animal metaphors, concrete-abstract relation metaphors (RAK), and synesthetic metaphors, and (c) the similarities between vehicle and tenor; metaphor is created based on the similarity between the reference of something that is compared (tenor) with the reference of something that is used as a comparison (vehicle). Based on the research results, it can be suggested that the use of metaphors in the mass media needs attention, especially for language researchers.
\end{abstract}

Keywords: Analysis, metaphor, journalism

\section{Introduction}

In a discourse, a journalist not only conveys the main message through the text, but also figures of speech, expressions, metaphors as ornaments or ingredients of news. The use of certain metaphors is the main clue in understanding the meaning of a text. Certain metaphors are used by journalists strategically as a basis for thinking, justifying reasons for certain opinions or ideas to the public. Journalist's takes advantage of the potential of language through everyday expressions, proverbs, noble advices, ancient words, even through expressions taken from scriptures to strengthen the main message conveyed.

In order to create the ideal news, journalist's uses diction and language style so that the message conveyed can be received by readers according to the expected target. Based on the direct meaning or absence of meaning, language styles are divided into two, namely rhetorical language styles and figurative language styles. The rhetorical style of language emphasizes the use of specific expressions to create certain rhetorical effects. The figurative language style or figure of speech emphasizes the continuity of the meaning of the expression. In this case the writer uses an expression which has a different meaning than usual. According to Furniss [4], a 
word, phrase, or statement is figurative when it cannot be taken literally. In other words, there are figurative words or phrases that cannot be literally true in any circumstances. Therefore, when a statement cannot be literally true, people will automatically understand it in a figurative sense. On the other hand, Thompson stated that figurative language is a way of saying something other than using the literal meaning of words.

Furthermore, Taylor [14] has classified figurative expressions into three groups. Those are comparison and substitution, Representation by substitution, and contrast by discrepancy and inversion. In the part of comparison and substitution consist of simile, metaphor, allusion, metonymy, analogy, and allegory. Metaphor is an analogy identifying one object with another and ascribing to the first objects more quality than the second [10]. Moreover Wren and Martin said that a metaphor is an implied Simile. It does not like the simile, state one thing is like another or acts as another, but takes that for granted and proceeds as if two things were one. It is made more vivid by transferring to it the name or attributes of some other objects [13].

One of the journalists' efforts to perpetuate the packaging of information to their readers is to use metaphors. In essence, metaphor is a process of enriching or developing the lexicon of a language. This is also seen as a form of language creative power in the application of meaning.

Many researches have been done in the field of metaphor analysis. Raharta \& Hamsia [11] revealed an analysis of metaphor in Maya Angelou's "Caged Bird" and "Still I Rise" Poems. Al- Ali [2] revealed the functions and linguistic analysis of metaphor in the Holy Qur'an. Ndraha [9] revealed analysis of metaphor in Westlife's song lyrics. Then, Monika [8] revealed analysis of metaphor in 'a family affair' by Kate Chopin. However, none of them reveal metaphora analysis on Journalistic. Therefore, this research will focus on Metaphora Analysis on Journalistic Diversity (Discourse Study on Jawa Pos Newspaper).

This study aims (1) to describe the forms and types of metaphors used in the news discourse of the Jawa Pos newspaper and (2) to describe the relationship between the lexical meaning and the figurative meaning of metaphorical expressions used in the news discourse of the Jawa Pos newspaper.

\section{Method}

Research on metaphorical analysis in various journalism, particularly discourse studies in newspapers, is still feasible to conduct. Among the various existing media, only newspapers as the data source for this research. The data required is especially taken from the main news discourse in newspapers in general, namely political, economic, sports, social, criminal and entertainment news. Meanwhile, the type of newspaper referred to is the national published newspaper in Indonesian, namely the Jawa Pos daily newspaper.

In order to analyze the forms and types of metaphors, the agih method is used with the basic technique for Direct Elements (DE) and advanced techniques of changing techniques and techniques of changing the form (paraphrasing). In analyzing the comparison between the lexical meaning and the metaphorical meaning of the expressions under study, the equivalent method is used. 


\section{Results and Discussion}

\subsection{Figurative language and metaphor}

Waddel [15] states that figurative language is "the fresh, picture-making phrase that says one thing but means something different or something more" an expression that creates a fresh picture, which says something but the meaning is something else. Or something more '. From several kinds of figurative language that exist, this research will focus on metaphors. Furthermore, [15] explained that the metaphor is an implied comparison. It is implied because you do not say that something is 'like' or 'as' another thing; you simply say that one thing is something else (A is B).

One form of metaphor is personification. Rice stated; a form of metaphor is personification, a figurative device in which a writer attributes to something inanimate the powers of the living. Personification is generally relies upon verbs. In this connection, Gorys Keraf [6] states that personification is a kind of figurative language that describes inanimate objects or inanimate objects as if they have human characteristics. Personification (recognition) is a special feature of the metaphor in which inanimate objects act and speak like humans.

According to syntactic point of view, the metaphor can be distinguished from the type of lingual unit which is 'metaphorized'. In reality the use of metaphors is mainly shown through the lingual units of verbs and nouns. In this regard, Rice [12] mentions' a metaphor is an implied comparison, usually illustrated in noun structures, in actual practice, however, metaphors occur at least as frequently in verbs and verbal, where they can possess a subtlety and grace. They often lack in their starker noun forms'. Furthermore, Wahab [1] divides metaphors into three, namely nominative metaphors (in the form of nouns, both as subject and object), predictive (which appear in predicate form) and sentences (which are shown in all components of the sentence).

The use of metaphors that are disproportionately linked to the context will be counterproductive. Sometimes people mistakenly assume that by using a lot of figurative language, including metaphors, their writing will be more "expressive" and "lively". Windschuttle states that in Shakespeare's day the use of 'figurative' in everyday speech was common. However, he cautioned that uncontrolled use of metaphorical expressions has the potential to turn a passage into a joke "turning an essay into a joke". He added, 'the best rule to follow is to avoid using them except for special occasions. Used frequently, they appear pretentions; used rarely, they can be just right for those occasions when a striking phrase is really warranted. Therefore, the appearance of metaphors too often will give the impression of being grandiose, but the occasional use will actually be right (target).

\subsection{Variety of journalism}

Variety of journalistic languages is the variety of languages that are related to or have the characteristics of journalism, especially marked by the appropriate literary quality for popular newspapers and magazines. Journalism is a collection or editing of material about current interests for presentation through the media: newspapers, magazines, news films, radio and television. Gove stated, journalistic, relating to, or having the characteristic of journalism or journalistic, especially marked by literacy qualities appropriate to newspapers and popular magazines journalism, the collection and editing of material of current interest for presentation through the media of newspapers, magazines, newsreels , radio, and television (Gove in [6]. Therefore, journalistic work includes writing that is displayed in both print and electronic media. 
Rosihan Anwar explained that the characteristics of journalistic language are short, concise, simple, fluent, clear, straightforward, interesting and standard. What is meant by short, fluent and clear is seen from the speaker. Solid characteristic in terms of content. The nature is simple, straightforward and standard in terms of language.

The appearance of a newspaper news discourse cannot be separated from 'textual rhetoric', which is the way in which a text or discourse is structured using language. Leech [7] suggests four principles in textual rhetoric, namely (1) processability, (2) clarity principles, (3) economic principles, and (4) expressiveness principles.

a. Processability principle

News writers are basically encouraged to present facts in such a way that readers can quickly understand them (immediately). In order to realize this, the systematic presentation is certainly related to how to classify messages, determine the level of the role of messages and sort them with strategic systematic. This presentation structure should be in line with the habitual patterns of each language. English adheres to a syntactic structure with a 'light' syntactic structure pattern (light constituent) preceding the 'heavy' syntactic structure (heavy constituent). However, journalistic discourse in Indonesian is usually the syntactic structure that is important (heavy) precedes the less important (light).

b. Clarity principle

In accordance with the essence of a newspaper news discourse, which is to be present to readers to convey a fact, then news discourse writers must realize this principle in their writing. The trick is to use words that do not create ambiguity in the reader. Thus misunderstanding or misperception by readers will be avoided. This principle requires the use of words that contain literal meanings rather than metaphorical meanings.

c. Economic principle

Economic principles emphasizes the need to display short news texts in a limited space, without having to reduce the integrity of the content that needs to be informed. The text is short but content-dense will help readers save time and effort in understanding it. In order to realize this principle, various journalistic discourse writers usually reduce several syntactic constituents with abbreviations (abbreviations or acronyms), penetration (ellipsis), and pronunciation.

d. Expressiveness principle

This principle can be called the principle of iconicity related to the ordering pattern of aspects of the message. The author has strategic reasons which aspects are put forward first and which are put forward later. For example, facts in the form of causal relationships, chronology, genealogy and so on. Newspaper news discourse needs to consider this principle in an effort together with the other principles above so that the content of the news is quickly absorbed by readers.

\subsection{Form of metaphor speeches}

In order to analyze the form of metaphorical speech, this study cites the opinion expressed by Abdul Wahab [1] which classifies metaphors from a syntactic perspective. In this classification, metaphors are classified into (1) nominative metaphors, (2) predicative metaphors, and (3) sentence metaphors. The nominative metaphor can be divided into two: at the subject position it is called a nominative metaphor or nominative and at the object position it is called a complimentative metaphor.

However for the sake of practicality in this study, the mention of these metaphorical forms is changed to (1) a nominative metaphor, namely a kias symbol that appears only in the subject of a sentence, (2) a complimentative metaphor, namely a symbol of clas that exists only in 
objects or complements, (3) ) predicative metaphors, namely the symbols of kias that exist only in predicates, and (4) metaphors of sentences, namely symbols of clas that are found not only in the position of the subject, predicate or complement separately, but at least in the subject and predicate as a minimum requirement for the formation of a sentence .

Based on the data collected from the discourse of the Jawa Pos newspaper, the four metaphors can be described as follows.

a. Nominative Metaphor

Speeches that contain metaphorical meanings are categorized as nouns, especially those that act as the subject of sentences. The position of the subject is always filled with nouns, so this metaphor is a subjective or nominative metaphor only. The following examples contain nominative metaphorical speech.

He did not explain when and how the cursed object was placed. In the sentence data (1) there is a nominative metaphor for the cursed object as the subject. The word cursed usually describes things related to human evil, for example in sentence (1a) cursed is a child who dares to his parents. However, in sentence (1) the property is transferred to objects. The cursed object reference referred to here is a bomb, which has the likeness of a bad person, which is always harming others.

b. Complimentative Metaphor

In complimentative metaphors, speech which contains metaphorical meaning is also categorized as nouns, but does not function as a subject. The metaphor of this form can be seen in the following sentence data. The New Year in Hong Kong was marked by demonstrations of thousands of citizens demanding the full implementation of democratic life.

Sentence (2) contains complementary metaphorical speech, namely democratic life, which takes advantage of the similarity of life in plants, animals or humans to 'life' in democracy. Democracy is a system of government that is administered by the people through their representatives or is called people's government. Practically, this system is implemented differently from one country and another. The level of democratization of society cannot be separated from the understanding, situation and interests of the individual society itself. Democracy has had a long history, from its inception, development, acceptance and opposition by the people, extinction to its quite diverse implementation today. All this is same with the life processes of living things in general, which are very varied and there are always developments or changes from time to time.

c. Predicative Metaphor

In the predicative metaphor, words that have a kias symbol are in the predicate position, and other sentence components have denotative meaning, as in the following sentence data. There were no prominent criminal actions that tarnished order and security both before and after the turn of the year.

The predictive metaphor in sentence (3) is tarnishing. The word tarnish means to make something dirty with stain, that is, a kind of spot that comes from a liquid. In the lexical sense, tarnish is used with a concrete object, for example in the sentence 'The child stains his friend's clothes with ink'. Speakers in sentence (3) juxtapose the word tarnish with an abstract object, namely "order and security". So he juxtaposes the abstract "order and security" with concrete objects such as clothes, tables, floors and so on.

d. Sentence Metaphor

In sentence metaphors, all sentence components contain symbols of kias. The author expresses his metaphorical speech not limited to the subject, predicate or complement, but to all of these components. Metaphors of this type can be seen in the following data examples. We have tragedies these days, but what happened in Iran is tens of times bigger. Sentence (4) We 
have been hit by tragedies these days; the coordinating minister told journalists after dispatching the medical aid team to Iran. Our subject is not limited to referring to speakers and speech partners (journalists), but to a broader reference, namely the Indonesian people. He intended that despite the condition of concern in our own country, which has experienced various natural disasters, the Indonesian government still sends humanitarian aid. The word overwritten literally means "to be crushed", and is usually followed by a concrete object that is heavy and burdensome (the subject). Followed by the abstract noun disaster, overwritten becomes a metaphorical meaning.

\subsection{Types of metaphorical speech}

The classification of metaphorical speech types is based on the opinion of Stephen Ullmann (1972). According to his reference category, Ullmann divides metaphors into four, namely anthropomorphic metaphors, animal metaphors, abstract-concrete relationship metaphors and synesthetic metaphors. This grouping is applied to metaphorical speech quoted from the news discourse of the Jawa Pos newspaper, as described below.

a. Anthropomorphic Metaphors

In anthropomorphic metaphors, there are word relations that should be used specifically for human features, but are associated with inanimate objects. This type of metaphor utilizes humans or members of the human body as a means of comparison, both as tenors (something to be compared) and as a vehicle (means of comparison). Metaphors like this can be seen in the following data examples.

(5) ... we can reflect on our lives, how far have we gone, have we met our target. Sentence (5) is a suggestion indicating that he has gone too far. I don't agree (describing the direction). In line with this example, the word stepping in sentence (5) above also has a metaphorical meaning which refers to an action, and the word distant means the quantity of the result of the action. So sentence (5) can be paraphrased like (5b) ... we can reflect on our lives again, how much we have done something, has everything been in accordance with our target Animal Metaphors.

Animal metaphors use the animal world as a source of comparative imagination. The metaphor of the animal is applied as a vehicle and tenor for humans and non-humans. In the first type, humans are compared to various types of animals such as dogs, cats, pigs, donkeys, geese, lions, wolves, and so on. In the discourse of the Jawa Pos newspaper, this type of metaphor can be seen in the following data examples.

(6) Based on a report at the Solo Police Headquarters on Thursday (1/1), the victim admitted that he did not forget to lock the handlebar. It turned out that in vain, the thief still stole the victim's motorcycle.

The metaphor in sentence (6) is the metaphor of an animal, which is usually carried out by animals, namely carrying something with their mouths. This expression can also contain the value of success achieved by hard effort. From sentence (6) it can be concluded that a thief can steal a motorcycle after with great effort he has succeeded in removing the lock on the motorcycle handlebar without anyone knowing it to be stolen.

b. Abstract-Concrete Relationship Metaphors (ACR Metaphor)

In this type of metaphor, Ullman provides examples of expressions that have abstract object references used to express concrete object references, or vice versa. In this type of metaphor, there are many abstract objects that are used as vehicles which are then concretized in their metaphorical meaning. Examples of this type of metaphor are often found in the discourse of the Jawa Pos newspaper as quoted in the following sentences. 
(7) "PLN is still trying to generate operating profit coupled with efficiency in all fields," he said. Sentence (7) contains the ACRM metaphor for making a profit. Verb printing is usually followed by a concrete object, such as 'printing money, printing books, and printing photos'. In this sentence the speaker equates abstract profit with concrete printed materials. The phrase making profit means 'making a profit'.

Synesthetic metaphor is a transfer of association, that is, from perceptions that actually match one of the senses is transferred to the other senses. Expressions can be created by transferring stimuli from one sense organ to another, for example from the sense of hearing to the sense of sight, from the sense of touch to the sense of hearing, and so on. Metaphors of this type are often found in the discourse of the Jawa Pos newspaper, as quoted in the following example.

(8) Along the path, Wynne received a warm welcome from the public. In data (8) there is a synesthetic metaphor, namely a warm welcome. The sentence above is quoted from a sports report about the visit of Wynne Prakusya and Angelique Widjaya to Solo, which received a warm welcome from their fans by traveling around the city. The excitement can be lived through the sense of sight, but in this sentence the speaker chooses warm words that can only be felt by the skin. In this case there is a diversion of responses from the sense of sight to the senses of taste (skin).

\subsection{The similarities between rides and tenors}

In the metaphor, the speaker makes use of the similarities between rides and tenors. Ullmann states that there are two kinds of similarities between ride and tenor that lead to metaphors, namely objective similarities and emotive similarities. Objective similarity is the similarity of two entities in terms of form, while emotive similarity is related to feelings.

Metaphorical speech data on the news discourse of the Jawa Pos newspaper have been divided into nine categories. In describing the similarity relationship the data were divided into nine groups, based on the category of human perceptual space in creating metaphors, which was introduced by Michael

C. Haley (in Abdul Wahab [1]). This classification is sorted from the category of perceptual space closest to humans as speakers of language, namely the Human category to the furthest, namely the Being (state) category. The complete sequence of the nine categories can be seen in the table 1 .

Table 1. The category of human perception space according to haley

\begin{tabular}{cccc}
\hline No & Category & Examples of Nouns & Prediction \\
\hline 1 & Human & Human & Think \\
2 & Animate & Animals & Walk, run \\
3 & Living & Plant & Grow \\
4 & Object & All Minerals & Can break \\
5 & Terrestrial & Mountain, river, oceans & Spread out \\
6 & Substance & A kind of gas & Inert \\
7 & Energy & Light, wind, fire & Move \\
8 & Cosmos & Sun, earth, moon & Need space \\
9 & Being & Truth, love & Exist \\
\hline
\end{tabular}

This classification of data according to the category of perceptual space is at the same time directed at finding the peculiarities of metaphorical speech, as it perceived from the human 
perception space in creating metaphors. In tables 2 to 9 above, the similar components of the vehicle (column 3) and the meaning of tenor (column 4) are in bold. These components become the common components of the vehicle and tenor, which are definitively stated in column 5.

\section{Conclusion}

Based on the description, it can be concluded as follows: (1) The forms and types of metaphors in the discourse of the Jawa Pos newspaper can be divided into four forms, namely nominative metaphors, complimentative metaphors, predicative metaphors, and sentence metaphors. (2) Metaphors in the news discourse of the Jawa Pos newspaper can be categorized into four types, namely anthropomorphic metaphors, animal metaphors, abstract-concrete relation metaphors (ACRM), and synesthetic metaphors. (3) The similarity between vehicle and tenor; metaphor is created based on the similarity between the reference of something that is compared (tenor) with the reference of something that is used as a comparison (vehicle). The relationship between the vehicle and the metaphorical tenor in the news discourse of the Jawa Pos newspaper can be divided into objective (form) similarities and emotive (perceptual / cultural) similarities.

The suggestions and recommendations of this study are (1) the use of metaphors in the mass media needs attention, especially for language researchers. In addition, it is necessary to prove the benefits of metaphorical speech for conveying ideas, it is also necessary to examine its weaknesses, both from a communication and linguistic point of view, (2) the results of this study are expected to add to the research repertoire of existing metaphors.

\section{References}

[1] A. Wahab, "Metafora sebagai Alat Pelacak Sistem Ekologi (Pelba 3).” Unika Atmajaya., Jakarta, 1990.

[2] Al-Ali, Ali., El-Sharif, Ahmad., \& Alzhoud, Mohamad Sayet. 2016. The Function and Linguistic Analysis of Metaphor in The Holy Qur'an. European Scientific Journal May 2016 edition vol.12, No.14 ISSN: 1857 - 7881 (Print) e - ISSN 1857- 7431

[3] E. Windshuttle, Keith \& Windshuttle, Writing, Researching and Communicating.

[4] Furniss, C. 1996. An Introduction to Poetry. Boston: Little Brown and Company.

[5] G. Leech, The pragmatics of Politeness, vol. 21. New York: Oxford University Press, 2014.

[6] Gorys Keraf, Diksi dan Gaya Bahasa. Jakarta: Jakarta: Gamedia Pustaka Utama, 2002.

[7] Martin, H. \& P. C. Wren. 1990. High School English Grammar and Comparison

[8] Monika, Ria. 2020. Analysis of Metaphor in "A Family Affair" by Kate Chopin. Journal of English Education Literature and inguistics Vol 3 (1) May 2020

[9] Ndraha, L.D.M. The Analysis of Metaphor in Westlife's Song Lyrics. Jurnal Education and development Institut Pendidikan Tapanuli Selatan Vol 3 (1) Edisi Januari 2018

[10] Pardede, M. 2008. Unpublished Undergraduate Thesis: Understanding Poetry. Medan: University of North Sumatra.

[11] Raharta, Akhbar Pradana., \& Hamsia, Waode . 2016. An Analysis of Metaphor in Maya Angelou's "Caged Bird" and "Still I Rise" Poems. Tell Journal, Volume 4, Number1, April 2016

[12] S. Rice, . Right Word, Right Place. California: Wadsworth Publishing Company. California: Wadsworth Publishing Company, 1987.

[13] Sudaryanto, Aneka Konsep dan Kedataan Linguistik, 1997th ed. Yogyakarta: Duta Wacana University Press, 1990. 
[14] Sydney: McGraw-Hill Book Company, 1990

[15] Taylor, R. 1981. Understanding the Elements of Literature. London: The Macmillan Press Ltd

[16] Waddell, Marie L, The Art of Styling Sentence. New York: Barron's Education Series, 1983. 